We ... had
to explain ...
the peculiar
ambient
oxidation
reaction and
the enhanced
catalytic
activity

$\Rightarrow 2$

\title{
The perfect defect
}

Transition metal dichalcogenides (TMDs) are robust layered materials that are prized for their semiconducting properties. This is particularly the case for the hexagonal monolayer form, the direct band gap (1.5-2.0 eV) of which makes it superior to graphene and multilayer 2D materials for certain electronics applications. Although these applications benefit from the relative stability of TMDs towards oxidation, this robustness can be a disadvantage when it comes to studying $\mathrm{MoS}_{2}$ in terms of catalytic activity or introducing defects. However, a team led by Levente Tapasztó now provides the first atomistic data for the aerobic oxidation of pristine monolayer $\mathrm{MoS}_{2}$ to $\mathrm{MoS}_{2-x} \mathrm{O}_{x}$. Their Nature Chemistry study shows this $\mathrm{O}$-doped material to have superior catalytic activity for the $\mathrm{H}_{2}$ evolution reaction (HER).

Ambient aerobic oxidation contrasts the typical means to introduce defects in $\mathrm{MoS}_{2}$ : harsh methods such as $\mathrm{O}_{2}$ plasma treatment, $\mathrm{UV} / \mathrm{O}_{3}$ exposure and high temperature $\left(>300^{\circ} \mathrm{C}\right)$ annealing. In air, the $\mathrm{S}$ atoms are slowly replaced by $\mathrm{O}$ atoms to give $\mathrm{MoS}_{2-x} \mathrm{O}_{x}$ with retention of crystallinity. The slow rate
(1 atom $\mathrm{min}^{-1} \mu \mathrm{m}^{-2}$ ) at which this doping occurs is reflective of the large kinetic barriers $(\sim 1 \mathrm{eV})$ associated with basal plane oxidation. In addition to this problem, analytical instrumentation must have high spatial resolution and be very sensitive to detect $\mathrm{O}$ atoms at $<3 \mathrm{~mol} \%$. Tapasztó and co-workers first supported a single $\mathrm{MoS}_{2}$ layer on $\mathrm{Au}(111)$, a substrate amenable to scanning tunnelling microscopy (STM) imaging at low voltages $(5-10 \mathrm{mV})$. Under these conditions, the $\mathrm{O}$ atoms in the newly formed $\mathrm{MoS}_{2-x} \mathrm{O}_{x}$ appear more brightly in STM images.

The oxidation process first involves $\mathrm{O}_{2}$ attack and removal of a $\mathrm{S}$ atom as $\mathrm{SO}_{2}$ to give $\mathrm{MoS}_{2-x}$ in an enthalpically downhill $(\sim-0.49 \mathrm{eV})$ process, as predicted using density functional theory (DFT) calculations. Filling this $\mathrm{S}$ vacancy with an $\mathrm{O}$ atom is, as one might expect, even more favourable $(\sim-4 \mathrm{eV})$. In contrast, the analogous substitution at a pristine $\mathrm{MoSe}_{2}$ basal plane is strongly endothermic $(+0.75 \mathrm{eV})$, with the overall barrier also being high $(\sim 1.5 \mathrm{eV})$. These thermodynamic and kinetic parameters are consistent with the heavier chalcogenides being much more stable to oxidation.

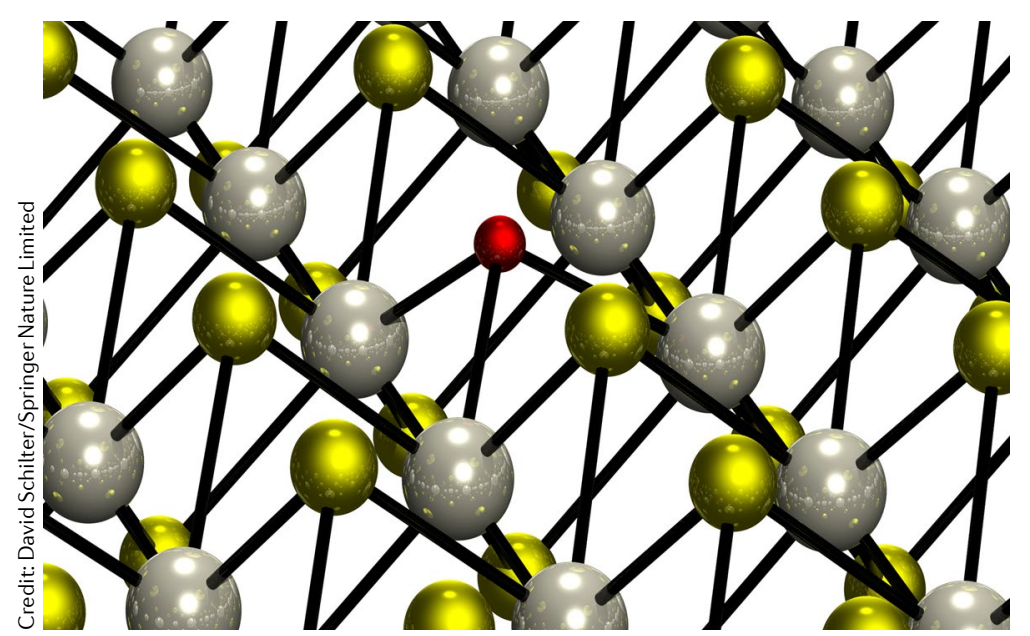

"We faced serious challenges and had to explain surprising, perhaps even counterintuitive findings in the case of both the peculiar ambient oxidation reaction and the enhanced catalytic activity of the $\mathrm{O}$-substituted sites," recalls Tapasztó. With exquisite control and understanding of the substitution process in $\mathrm{MoS}_{2}$, the team now had well-defined $\mathrm{MoS}_{2-x} \mathrm{O}_{x}$, a material they put to good use in the catalytic HER. After performing the HER separately on both freshly prepared monolayer $\mathrm{MoS}_{2}$ and a sample exposed to air for 1 year, it became clear that the defect material was more active. Indeed, this was reflected in a substantial increase in the current density and stability, even after cycling the potential 1,000 times. For example, the Tafel slope for $\mathrm{MoS}_{2-x} \mathrm{O}_{x}\left(67 \mathrm{mV} \mathrm{dec}^{-1}\right)$ is much shallower than that for $\mathrm{MoS}_{2}$ $\left(98 \mathrm{mV} \mathrm{dec}^{-1}\right)$ and comparable to that of $\mathrm{Pt}\left(54 \mathrm{mV} \mathrm{dec}^{-1}\right)$, such that the new material generates $\mathrm{H}_{2}$ with a lower dependence on applied potential. Indeed, introducing the electronegative $\mathrm{O}$ atoms affords sites with higher electron affinity $\left(-0.88 \mathrm{e}^{-}\right)$ compared with those in the parent material $\left(-0.47 \mathrm{e}^{-}\right)$. Combined with the $n$-doping, this affords a localized negative charge that better attracts $\mathrm{H}^{+}$ substrate to participate in reductive coupling to give $\mathrm{H}_{2}$.

Despite their encouraging results, Tapasztó notes that there is more to be done before the promise of these materials can be realized. It is not yet clear whether or not this substitution chemistry and catalytic behaviour is general for all transition metal sulfides and selenides. "Our intuition tells us there might be a general pattern, but of course one needs sound experimental evidence to prove that," concludes Tapasztó.

Prateek Dongare, Associate Editor, Communications Chemistry

ORIGINAL ARTICLE Pető, J. et al. Spontaneous doping of the basal plane of $\mathrm{MoS}_{2}$ single layers through oxygen substitution under ambient conditions. Nat. Chem. https://doi.org/10.1038/ 541557-018-0136-2 (2018) 